\title{
Astronomy at sea: Jim Wild's Cunard diary
}

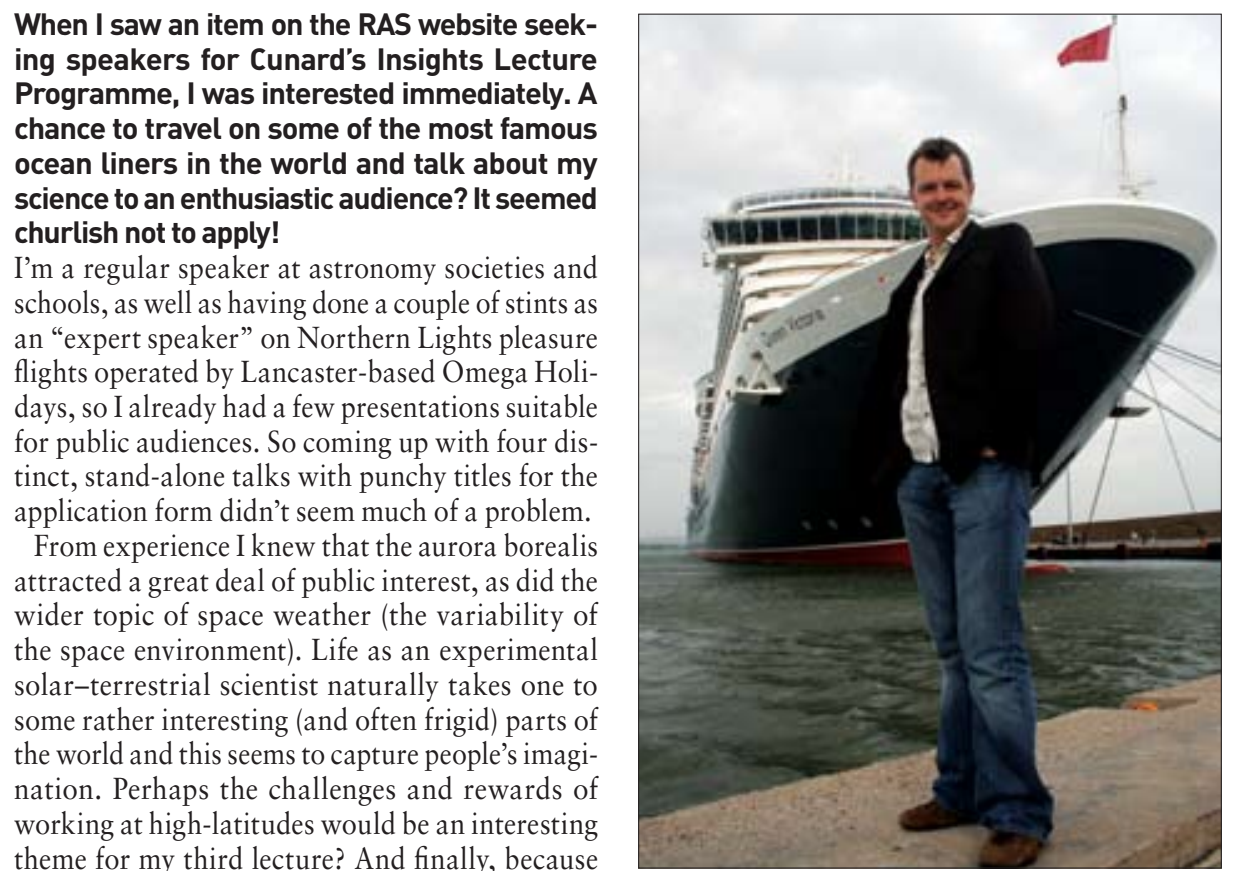
space always seems to be an appealing topic, a look at how our view of planet Earth has changed since the beginning of the space age would provide plenty of scope for an interesting talk.

I sent my application to Cunard and waited. After just a few weeks, the email arrived: could I join the MV Queen Victoria in Rome on 29 November for her Connoisseurs' Mediterranean cruise? It didn't take long to make that decision!

\section{Day 1: Saturday 29 November}

My wife and I embark at $7 \mathrm{pm}$ at the wet and windswept port of Civitavecchia, after a fog-delayed flight from Manchester to Rome. Once aboard, I find messages from the ship's entertainment team. After a quick briefing and a peek at the venue for the talks - the impressive Royal Court Theatre, seating 850 - there's just time for dinner and lifeboat drill before our late-night departure for Naples. The schedule of talks is almost identical to the schedule that Cunard had supplied three weeks earlier, except that my final talk on science in the polar regions isn't required after all. With my first talk planned for our first full day at sea (day 6) I have plenty of time to acclimatize to life on-board and see some of the other "Insights Programme" lecturers - an entomologist and a historian - do their stuff and pick up some tips.

\section{Day 2: Sunday 30 November}

I'm awoken at $8.30 \mathrm{am}$ by the phone in our stateroom. The entertainment coordinator tells me that, due to the bad weather, the ship will not be making her first scheduled stop in Naples. Instead, we are going to have a day at sea and make directly for our next port, Messina in Sicily. Could I be in the theatre ready to present a lecture at $10 \mathrm{am}$ ? I've embarked with my talks virtually ready to go, but because of the change of plans, I'm resurrecting my final talk. As I quickly go through my notes and get a shirt ironed, revised programmes for the day's entertainment (including my talk) are being circulated to the 2000 passengers.

At exactly $10 \mathrm{am}$, the ship's Entertainment Director strides onto the stage and after a few words about the RAS and the Insights Lecture

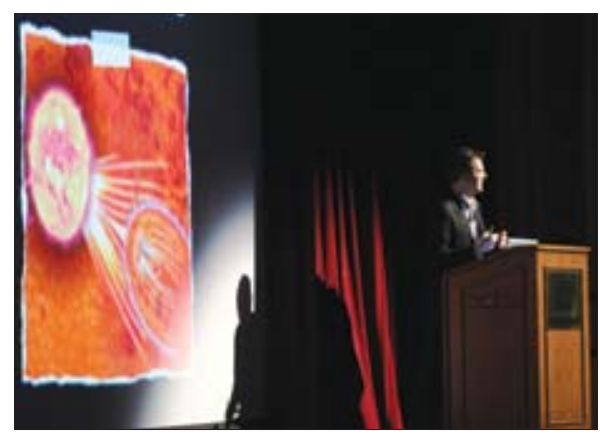

Jim Wild, as both tourist and lecturer. (Dawn Wild)

Programme, introduces me and my first lecture "It shouldn't happen to a scientist: science in the polar regions". Despite the last-minute change of itinerary, there are several hundred guests in the audience. All goes smoothly and there are several good questions from the audience at the end.

Later in the day, I am spotted by some members of the audience. To my surprise I find out that many of the guests on-board had already visited some of the locations I was talking about - such as Spitsbergen, Tromsø and even Antarctica - on other cruises and were thrilled to hear more about the science that went on there.

\section{Day 5: Wednesday 3 December}

My next talk is scheduled for 10 am on Thursday morning. I receive a message asking me to appear on the ship's own morning TV programme. The five-minute interview is a prime opportunity to let guests know something about me and what my talks will be about.

\section{Day 6: Thursday 4 December}

A "sea day" as the Queen Victoria sails from weather. The captain announces gale force 12 winds and $6 \mathrm{~m}$ seas. The $8^{\circ}$ list feels much more as the usually rock-steady Queen Victoria makes her way south. I don't expect a high attendance: although an impressive venue, three decks tall and bedecked in crimson and ornate gold decor, the Dubrovnic in Croatia to Valletta in Malta. Bad
Royal Court Theatre is windowless and in the bow of the ship - not necessarily the best place to be if one is feeling "delicate".

I had underestimated the guests! The theatre is filled with an expectant audience for "The aurora borealis: Nature's lightshow". Up on stage, the motion of the ship is pretty significant, but by holding on to the podium I keep my dignity. The swishing stage curtains provide a great prop when talking about "auroral curtains" and the audience seems incredibly enthusiastic. I get a hearty round of applause at the conclusion of my talk - in part for managing to stay on my feet, I suspect. And there are a people waiting for me in the lobby with some pretty searching questions.

\section{Day 9: Sunday 7 December}

In response to a note delivered to my stateroom, I meet with a passenger to have a chat and try to answer some questions. The gentleman concerned - a retired medical practitioner from the UK - not only has questions on my talks but on wider astronomy and science issues from stellar evolution to climate change. I think I manage to answer most of his questions in the 45 minutes we spend chatting in the grand lobby.

\section{Day 11: Tuesday 9 December}

My penultimate talk "Here is the space weather..." attracts another good audience. It seems that word-of-mouth is as important as the daily programme when it comes to advertising. Increasingly, I'm being approached on the ship and in ports of call by passengers who have been attending the lectures and the feedback is very positive. The number of people waiting in the theatre's lobby for post-lecture discussions is the biggest yet and I answer a stream of questions before taking a splinter-group, who are interested in finding out more about the "Friends of the RAS" scheme, for a post-lecture coffee and a chat.

\section{Day 12: Wednesday 10 December}

After almost a fortnight on-board, it's rather sad to be giving my final lecture, "Mission to planet Earth". Although I recognize many faces, there are still newcomers attending the lectures. Several passengers have told me that they missed earlier lectures but had been watching the taped re-runs on the ship's Insights TV Channel. Throughout the day, I'm approached by people who tell me how much they've enjoyed my lectures. The enthusiasm that Cunard passengers have shown for the diverse range of Insights lectures is genuinely impressive!

\section{Day 13: Thursday 11 December}

Disembarkation at Southampton - all good things must come to an end! The arrangement between the RAS and Cunard certainly seems to benefit all concerned. Cunard are provided with a diverse cohort of speakers to satisfy the demands of enthusiastic groups of passengers, the Society is able to promote its activities and the new Friends programme to an interested audience, and individual lecturers get the opportunity to give talks in a truly unique setting. Would I do it again? You bet - where do I sign up?

Dr Jim Wild is a solar-terrestrial scientist and lecturer in the Department of Communication Systems at

Lancaster University. 


\section{Telescopes in schools for IYA2009}

The Society for Popular Astronomy, Royal Astronomical Society and Science and Technology Facilities Council have teamed up to give free telescopes to 1000 secondary schools.

The project is part of International Year of Astronomy 2009, which celebrates the revolution in astronomy 400 years ago arising from the first use of the telescope. Telescopes for Schools aims for a similar revolution in school sciences, hoping to attract pupils to astronomy and space science, which children are consistently excited about, as well as the underpinning subjects such as physics and mathematics.

Participating schools will receive a DVD with clips explaining how to use their telescope and what they can look at. Further details are available on the Moonwatch section of the SPA website, specifically developed to support the Telescopes for Schools project. This will show teachers what they can observe on a clear night and it will have links to other resources and websites, including resources specifically identified by the RAS for use in schools.

http://www.popastro.com

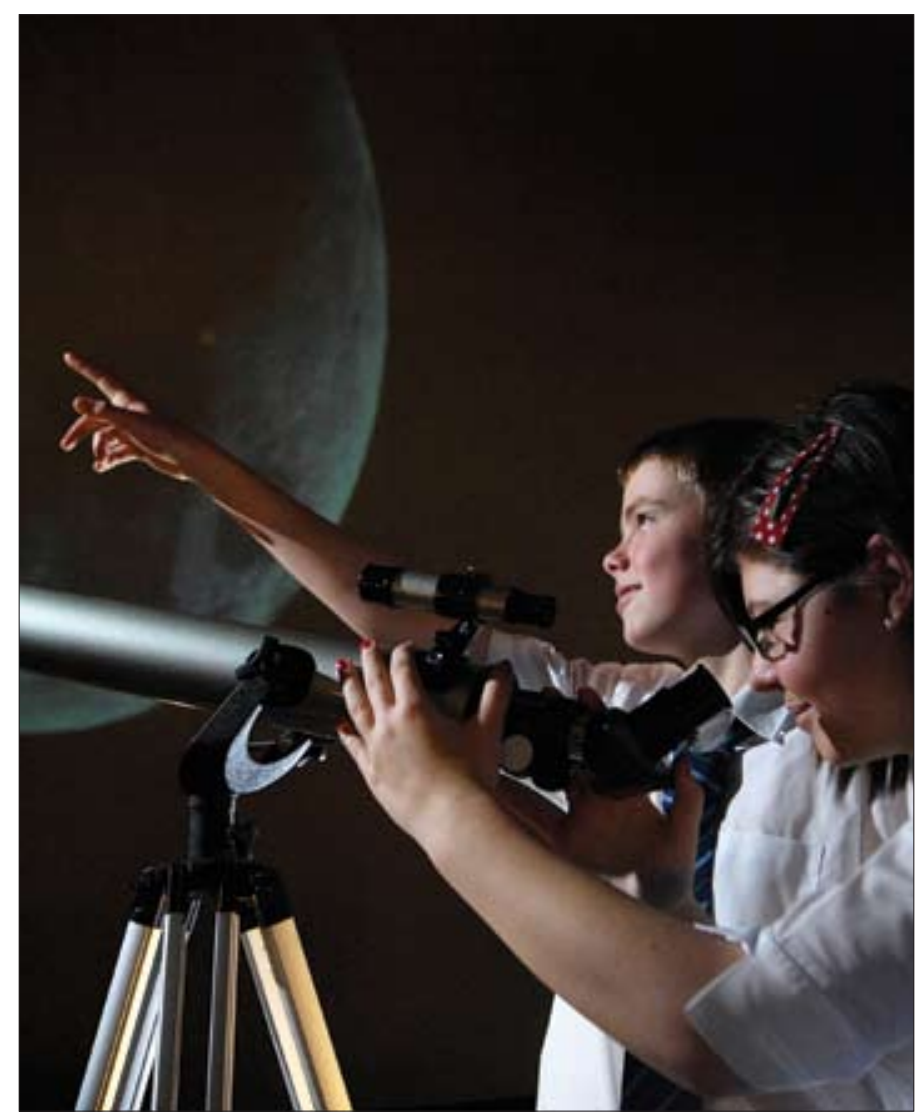

News IN BRIEF

\section{Library Saturdays}

It is anticipated that the RAS Library at Burlington House will be open for Fellows on the following Saturdays in 2009: 7 February, 7 March, 4 April, 9 May, 6 June, 4 July, 1 August, 5 September, 3 October, 7

November and 5 December.

Potential visitors are advised to confirm out-of-hours openings with the Librarian before undertaking lengthy journeys. http://www.ras.org.uk

\section{Speakers wanted?}

The RAS keeps a list of professional astronomers and space and planetary scientists willing to come and talk to schools on topics suitable for different ages. The speakers' titles and contact details are available on the RAS website, as are the distances they can travel. (Note that some speakers may charge expenses, although the talks are free.) Professionals with suitable talks should contact the RAS for inclusion on the list. http://www.ras.org.uk

\section{RAS extends IYA2009 grants}

The RAS's grants programme for IYA2009 has been such a success, with projects ranging from theatre productions to telescopes for schools, that the Council of the Society has extended it into 2009. Grants are offered to organizations (astronomical societies, educational establishments, heritage organizations etc) who wish to run events, exhibitions or other activities as part of IYA2009, especially (but not limited to) the cornerstone projects of special UK interest and especially (but not limited to) events taking place in the designated weeks. The RAS will distribute the grants in response to applications received in each of two rounds, with deadlines of 1 February 2009 (grants announced by 1 April 2009) and 1 August 2009 (grants announced by 1 October 2009).

Grants may only be offered to projects registered with the UK Project Office; a Project Proposal Document is available from UK Coordinator Steve Owens (steve@ astronomy2009.co.uk or tel: 07717 720479). (Applications for registration and an RAS grant may be made in parallel.)

The RAS will favour grant applications for activities taking place during the two National Astronomy
Weeks, referred to as the Autumn MoonWatch (Saturday 24 October to Sunday 1 November (for public events) and Thursday 19 November to Sunday 29 November 2009 (for schools projects), and under the umbrella of the cornerstone projects on which the UK is particularly concentrating (see the list below).

Applications should normally be for sums between $£ 250$ and $£ 5000$. Applications for amounts under $£ 2000$ will be favoured. Applications for amounts over $£ 5000$ should address this point explicitly. Applicants should make clear, given that time is running out to put on an event between the grant decision and the end of IYA2009, how the event is going to be staged effectively.

The 11 cornerstone projects in IYA2009 are $\left(^{*}=\right.$ of special UK interest):

- 100 Hours of Astronomy*

- The Galileoscope

- Cosmic Diary*

- The Portal to the Universe

- She is an Astronomer"

- Dark Skies Awareness*

- Astronomy \& World Heritage* - Galileo Teacher Training Programme - Universe Awareness*

- From the Earth to the Universe* - Developing Astronomy Globally. http://www.astronomy2009.co.uk

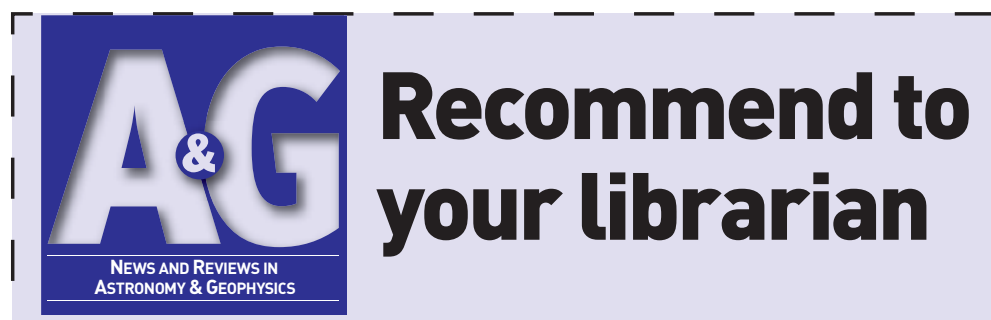

If your library had a subscription, colleagues and students could enjoy $A \& G$ too.

\section{Library Recommendation Form}

To: Acquisition Librarian

I recommend the library subscribe to $A \& G$ (ISSN 1366-8781)

From:

Dept:

Signature:

Date:

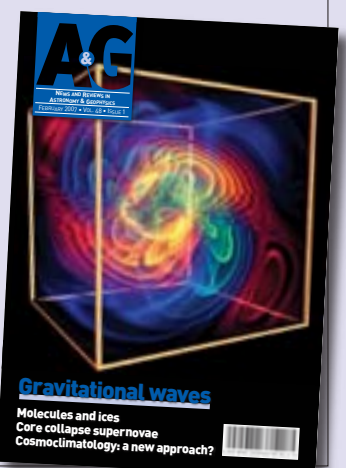

